AperTO - Archivio Istituzionale Open Access dell'Università di Torino

\title{
Geological map of the Monviso massif (Western Alps)
}

\section{This is the author's manuscript}

Original Citation:

Availability:

This version is available http://hdl.handle.net/2318/138939

since

Published version:

DOI:10.1080/17445647.2013.842507

Terms of use:

Open Access

Anyone can freely access the full text of works made available as "Open Access". Works made available under a Creative Commons license can be used according to the terms and conditions of said license. Use of all other works requires consent of the right holder (author or publisher) if not exempted from copyright protection by the applicable law. 
GEOLOGICAL MAP OF THE MONVISO MASSIF (WESTERN ALPS)

Gianni Balestro $^{(1)}$, Gianfranco Fioraso ${ }^{(2)} \&$ Bruno Lombardo

QUATERNARY DEPOSITS

Fin $\square$ -

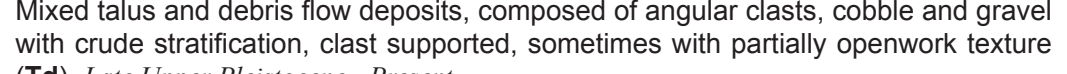

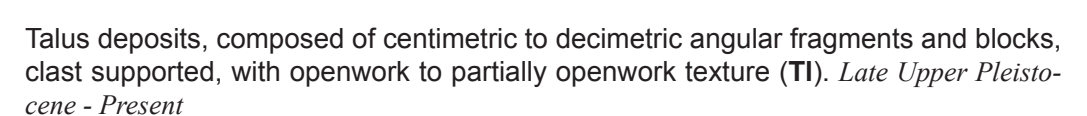

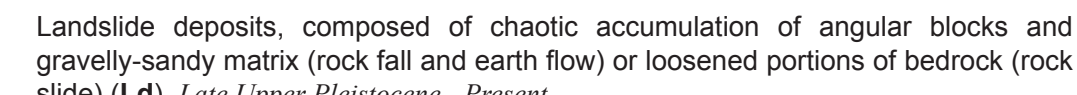

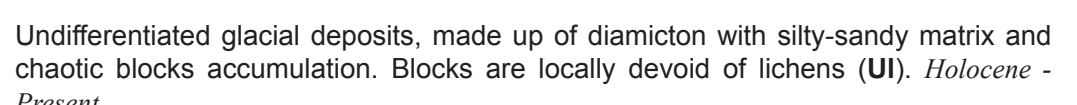

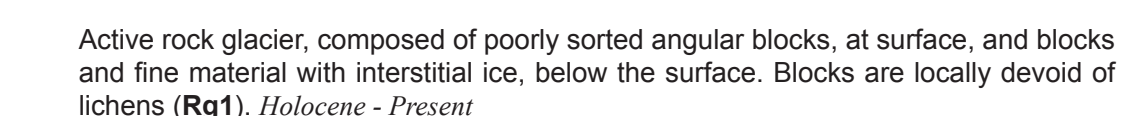

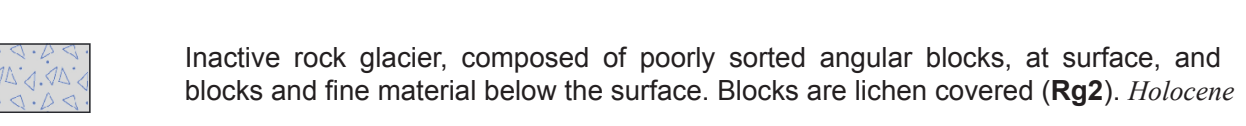

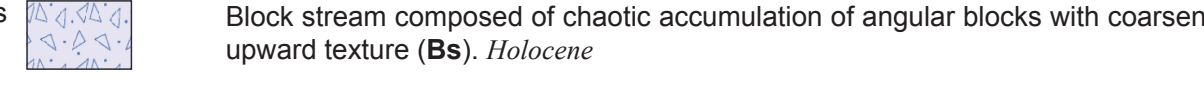

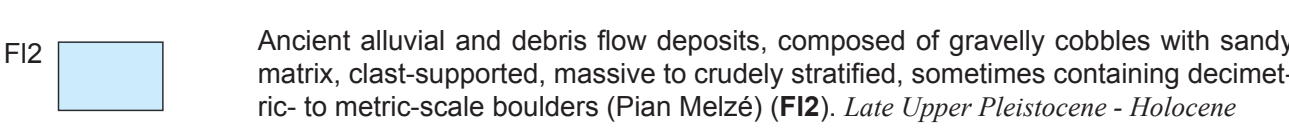

U. QUEYRAS Schistes Lustres

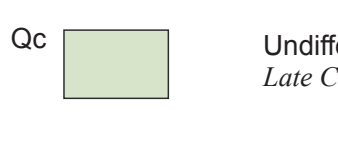

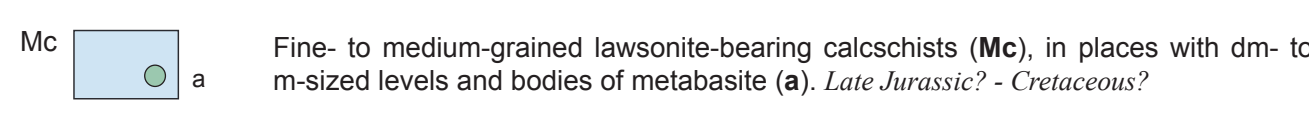

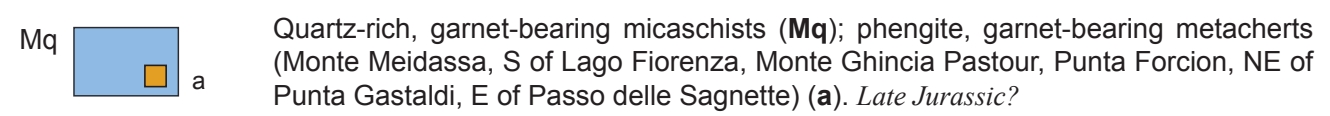

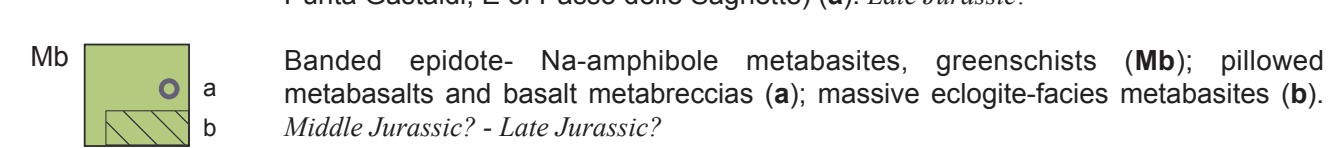

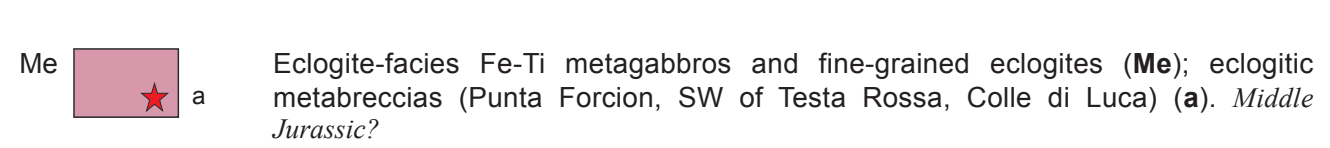

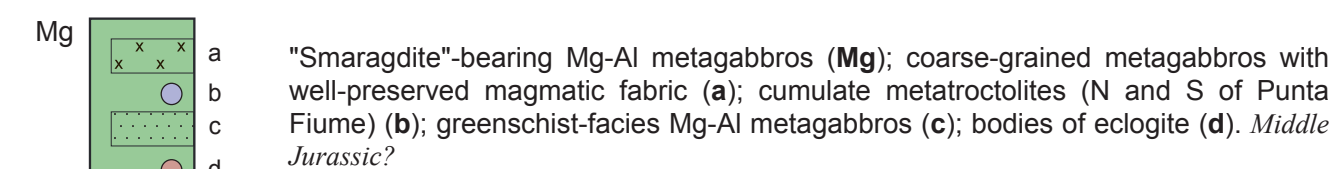

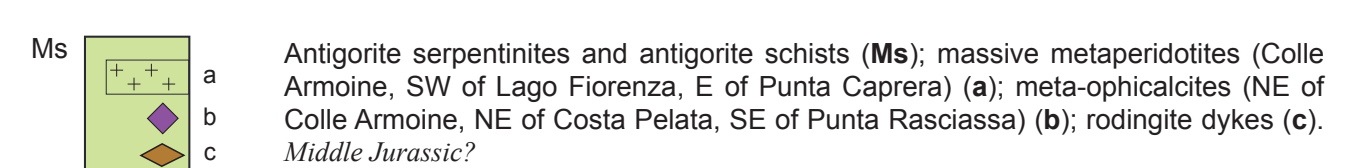

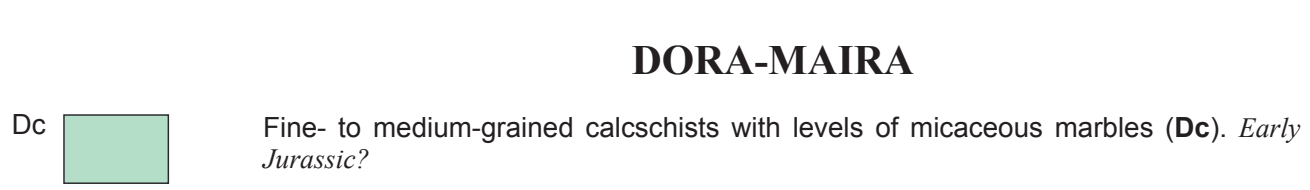

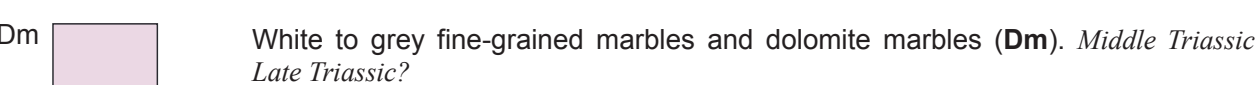

${ }^{\mathrm{Dq}} \square$

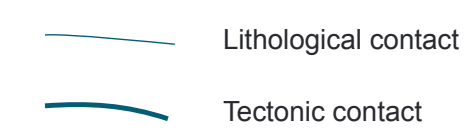

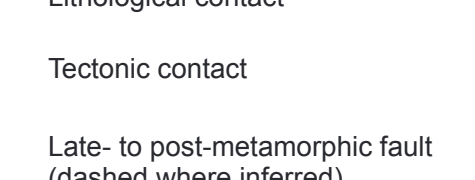

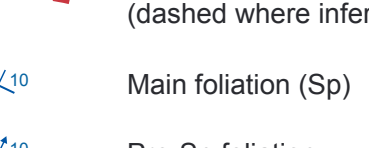

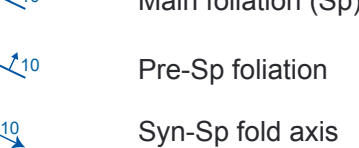

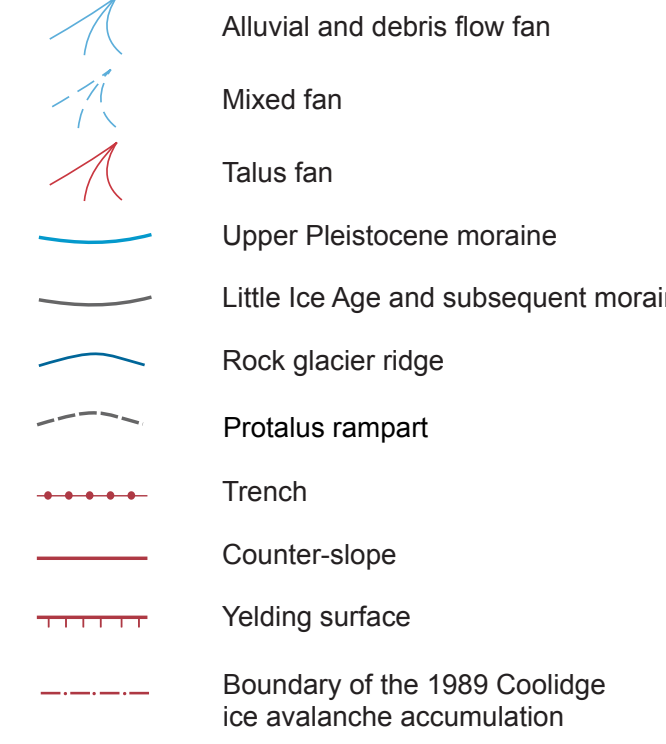

$$
\begin{aligned}
& \begin{array}{l}
\text { Pos } \\
*
\end{array}
\end{aligned}
$$

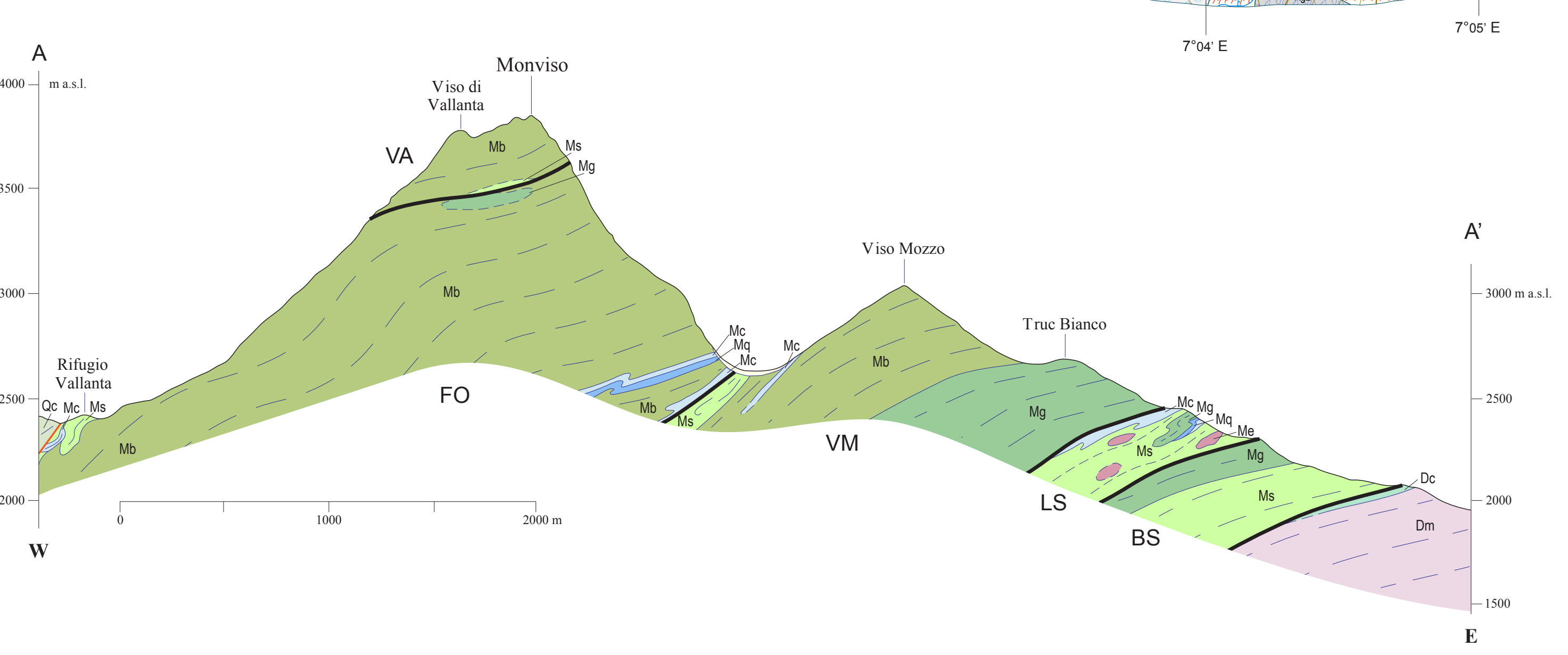

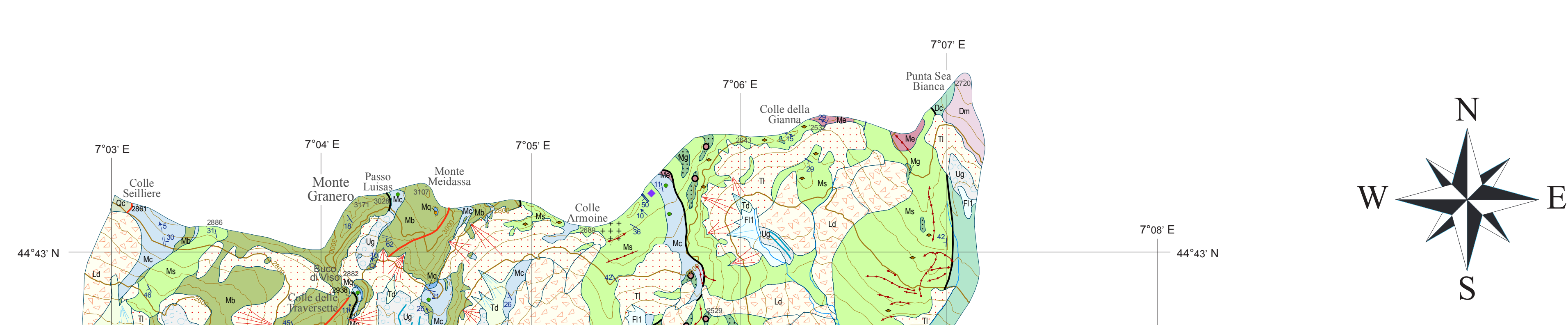

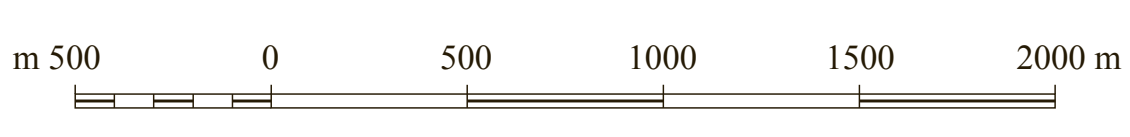

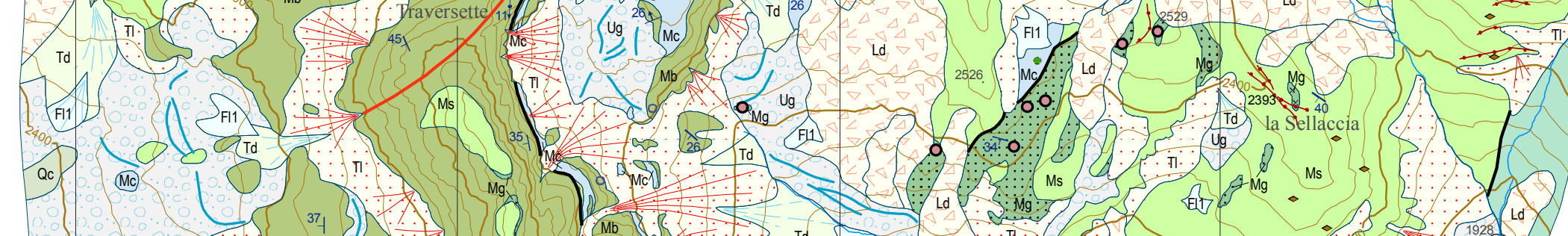

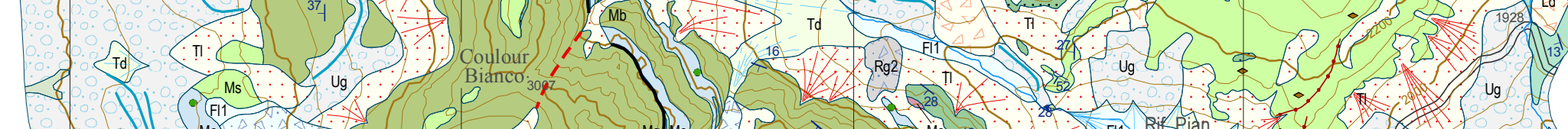

- 20 is

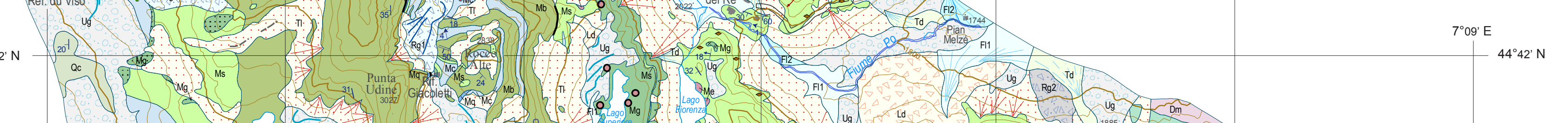

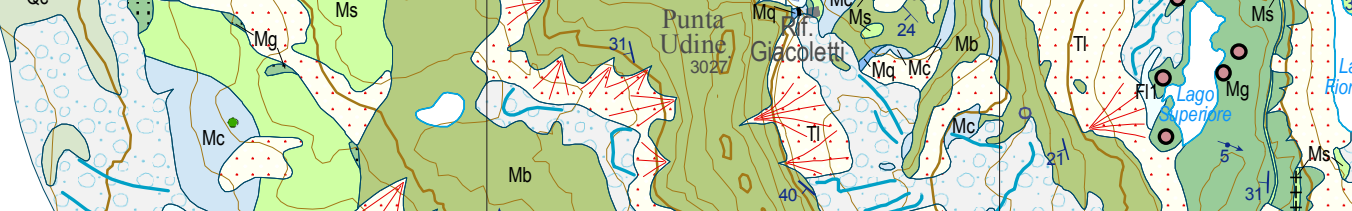
- 21 (n)

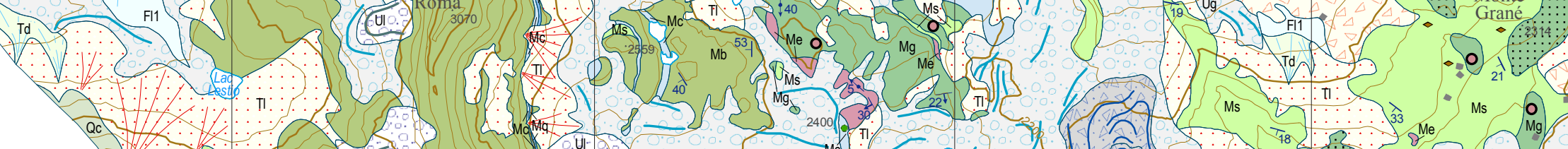

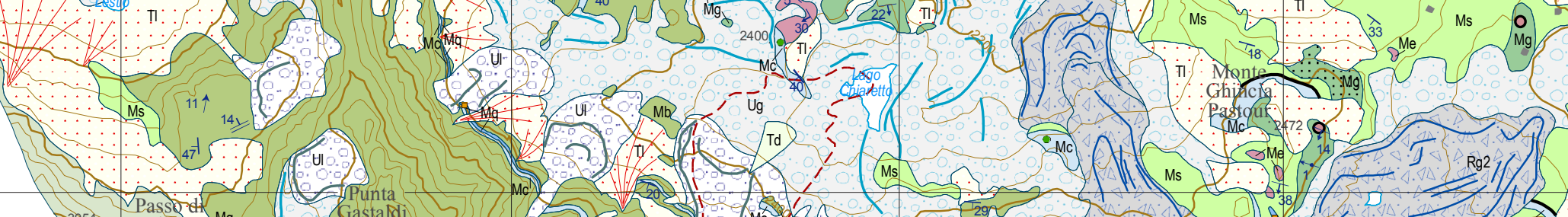
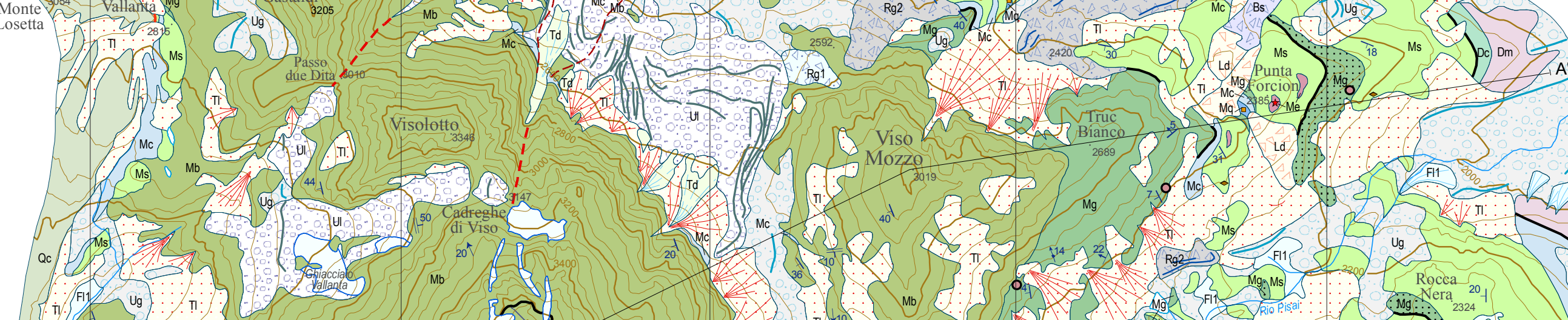

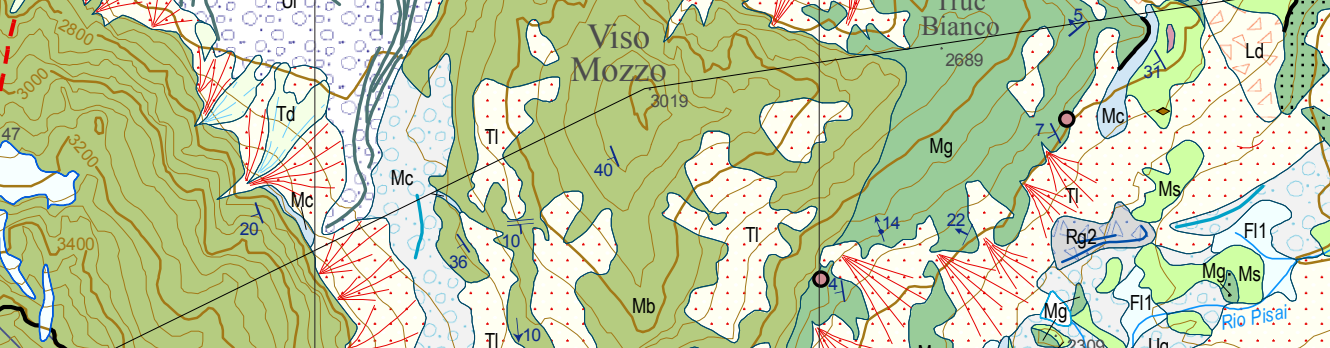

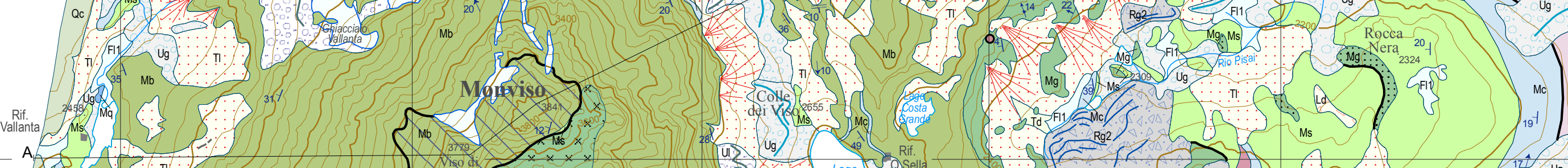

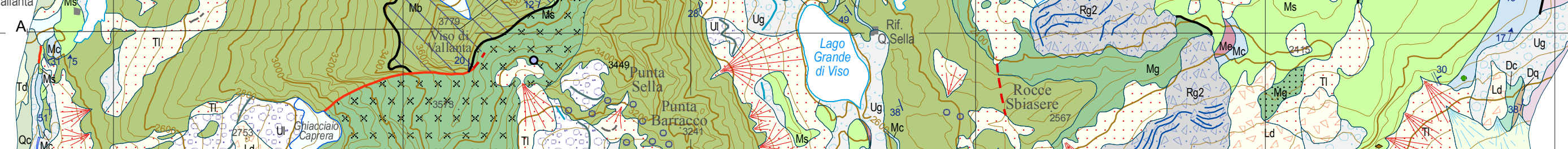

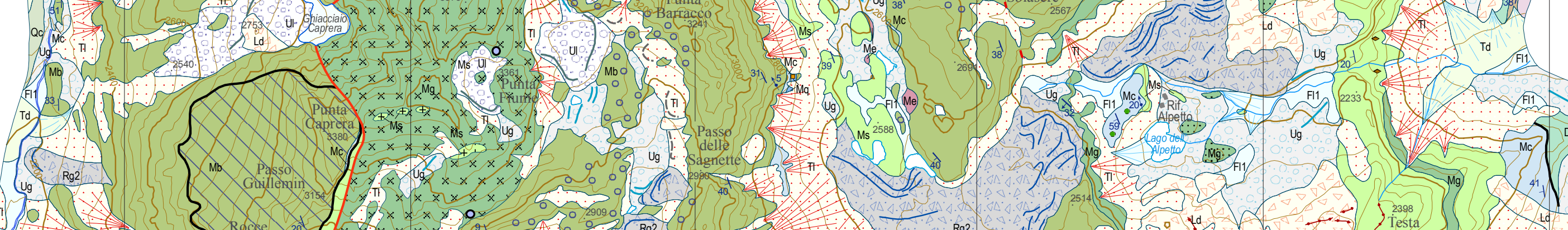

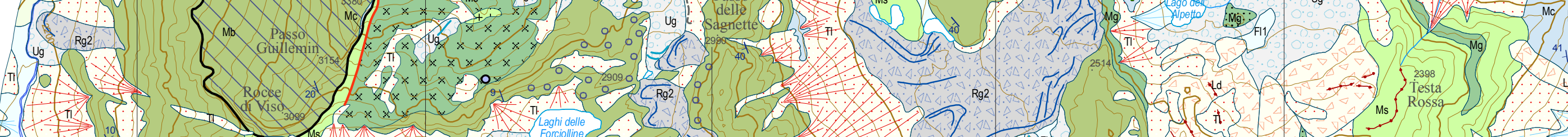
(1)

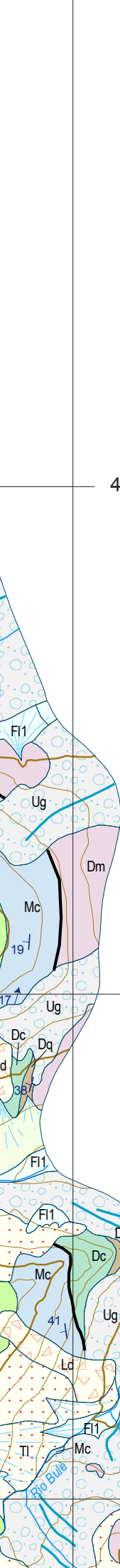

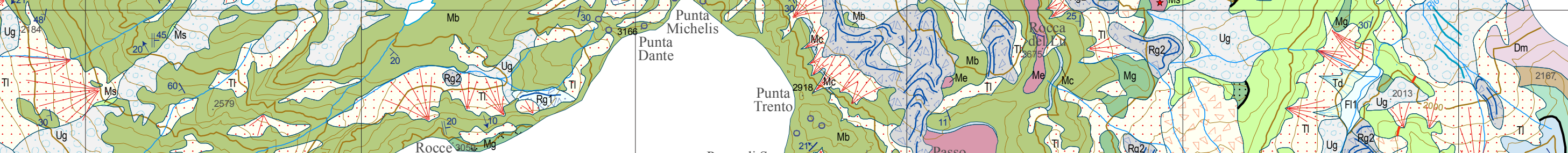

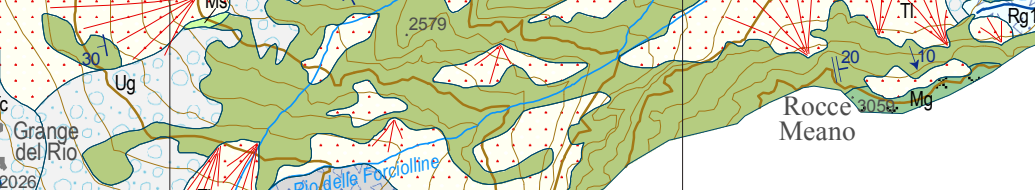

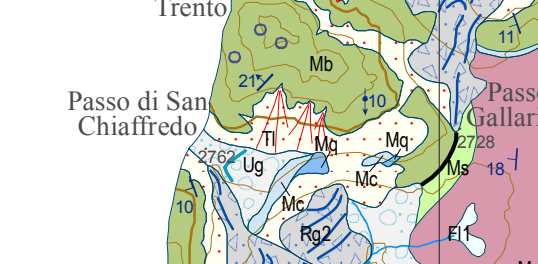

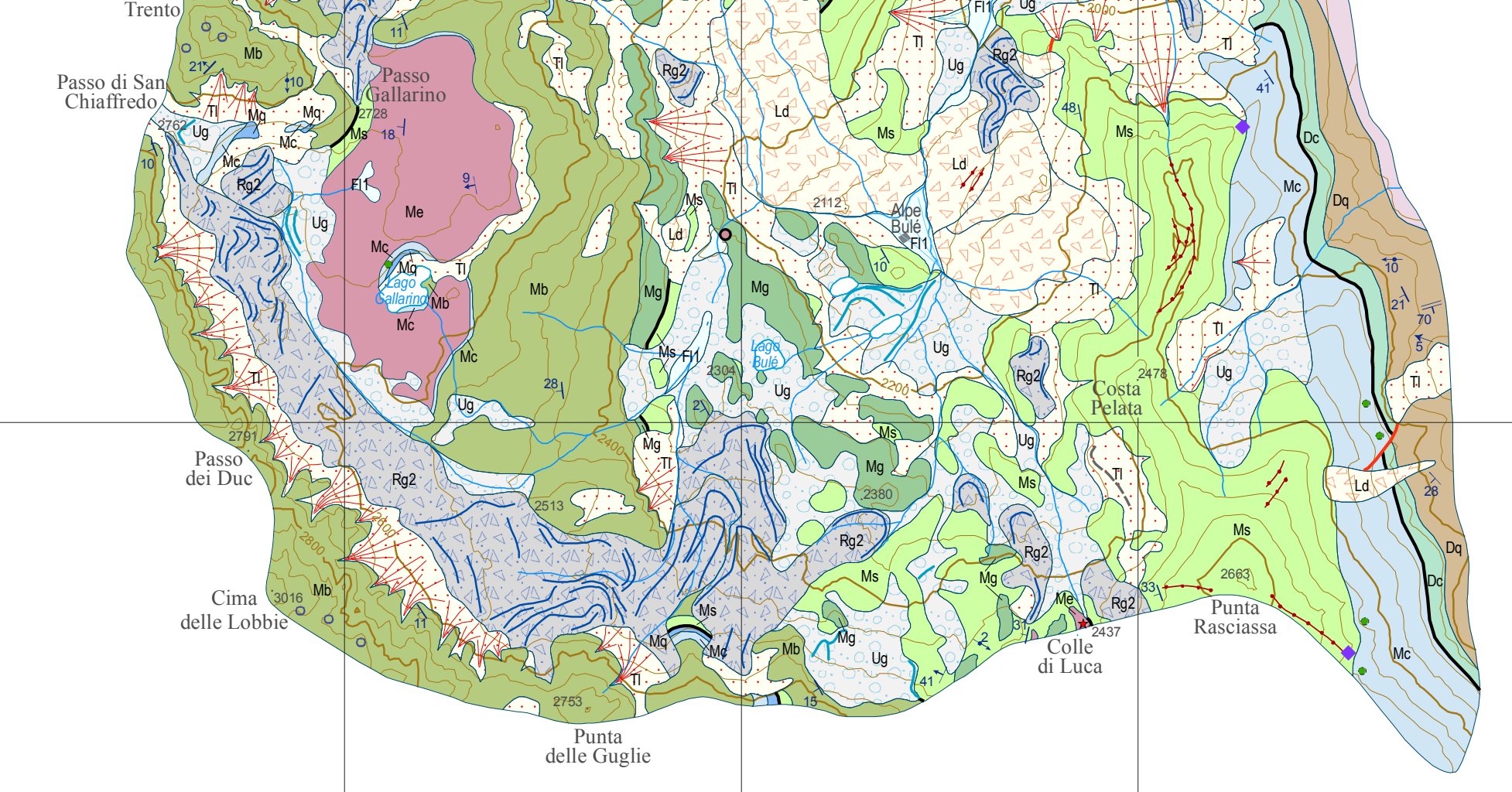

Tectonic map of the Western Alps
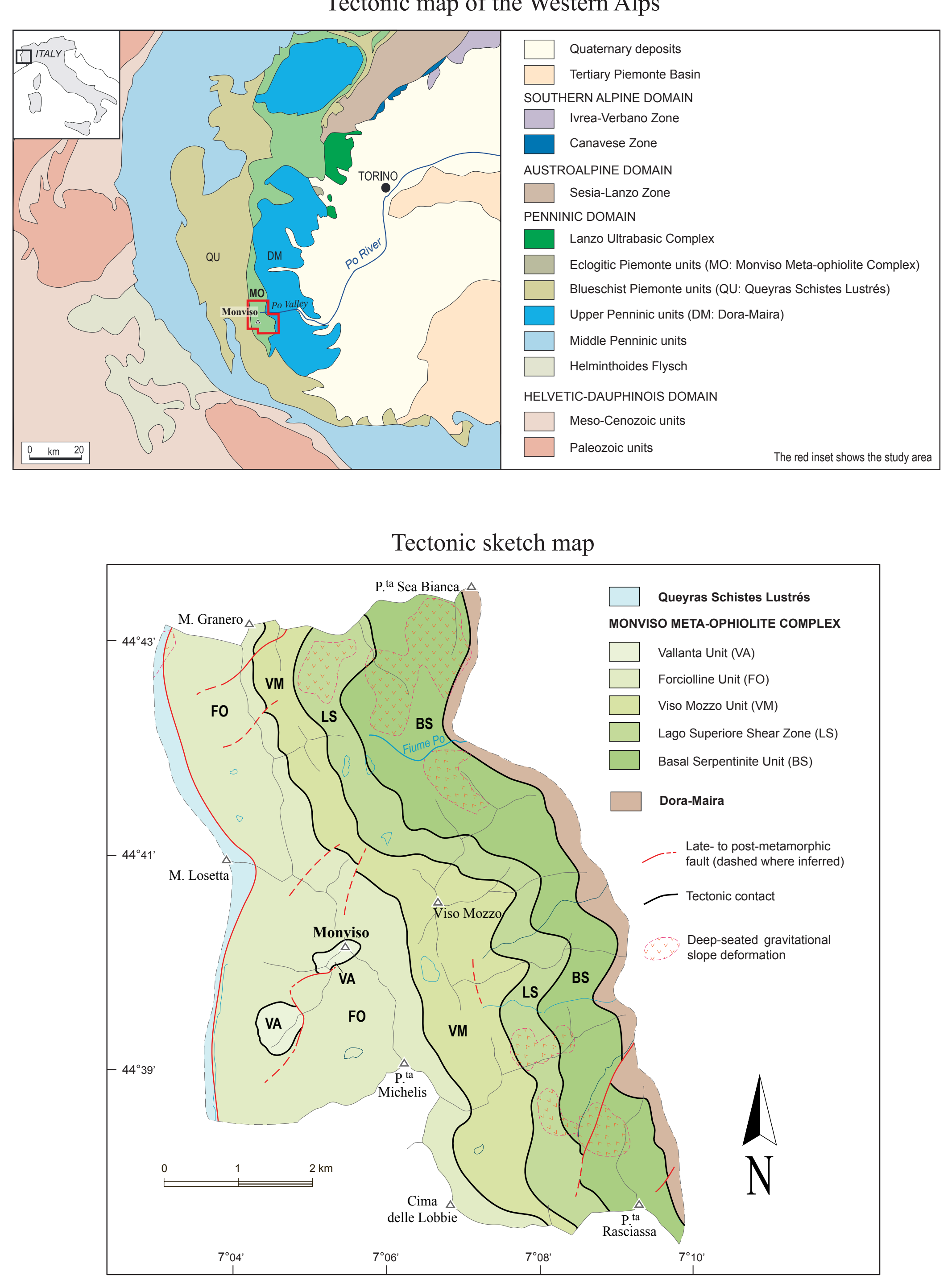

Ice-flow pattern of glaciers during the Last Glacial Maximum

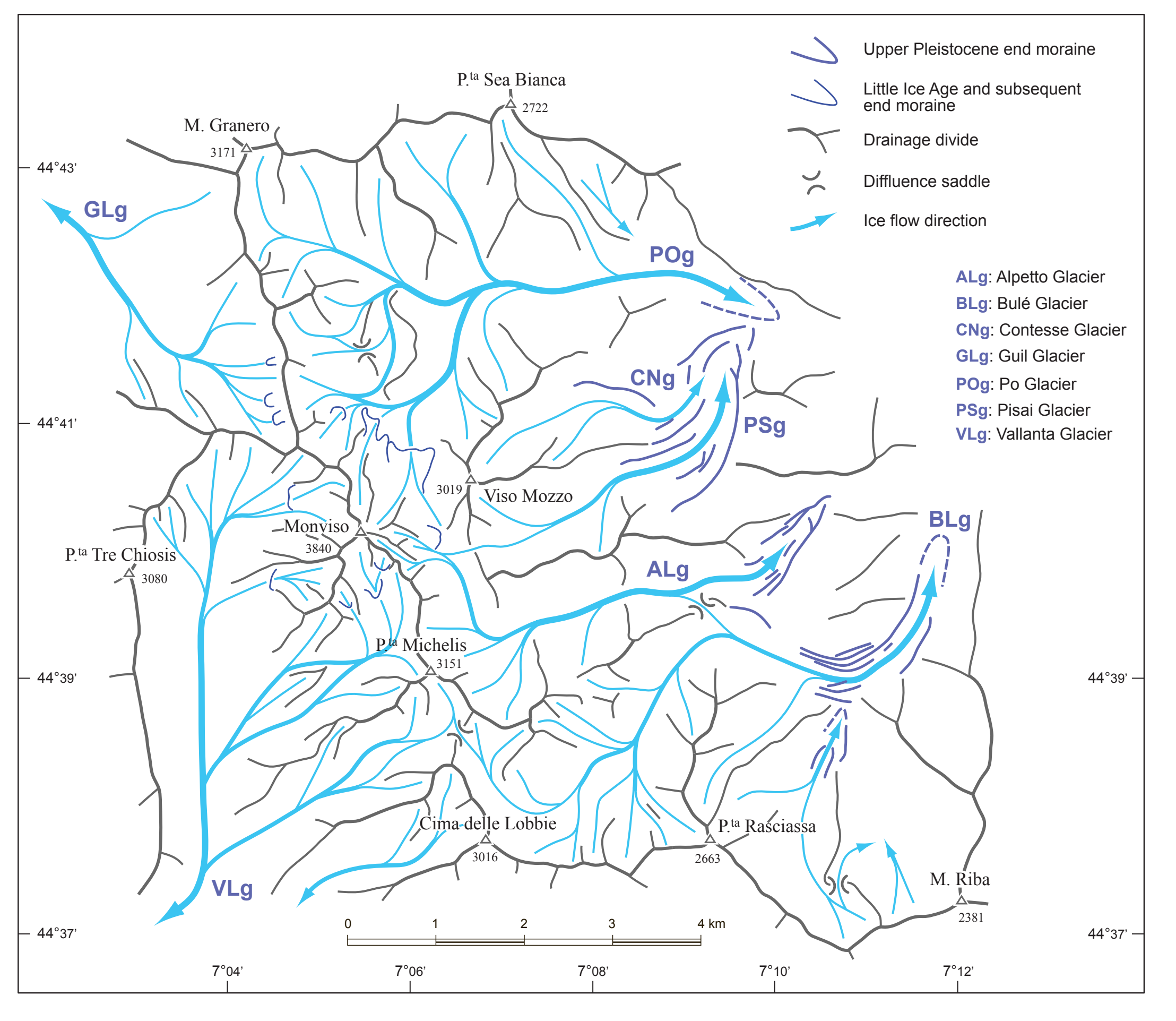

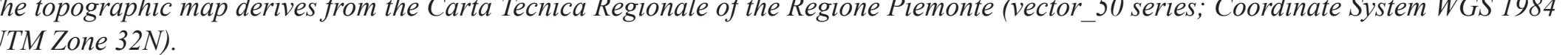

